\begin{tabular}{|l|l|l|l|l|l|}
\hline J. Tek. Ling & Vol. 12 & No. 3 & Hal. 277 - 282 & Jakarta, September 2011 & ISSN 1441-318X \\
\hline
\end{tabular}

\title{
PENGOLAHAN EFLUEN REAKTOR FIXED BED SECARA KOAGULASI
}

\author{
Indriyati dan Diyono \\ Peneliti di Pusat Teknologi Lingkungan-TPSA \\ Badan Pengkajian dan Penerapan Teknologi
}

\begin{abstract}
Abstrak
effluent dari reaktor fixed bed pengolahan limbah cair pembuatantahu masih mengandung organik tinggi dan memiliki banyak padatan tesusensi, sehingga warna air limbah tidak cukup jernih , dan sulit diturunkan secara anaerob. Tujuan percobaan dari proses ini dalah untuk menghasilkan air limbah untuk embuatan tahu menjadi lebih jernih. berdasarkan alasan diatas, maka dilakukan pengolahan limbah cair dengan menggunakan proses koagolasi menggunakan Alumunium sulfat dan $\mathrm{Ca}(\mathrm{OH})_{2}$ yang ditambahkan ke efluen reaktor fixed bed dengan variasi dosis sulfat Alumunium : mulai dari 0,$5 ; 1,0 ; 1,5 ; 2,5 ; 5,0 ; 7,5$ gramdan batuan $\mathrm{Ca}(\mathrm{OH}) 2$. Akan meningkatkan alkanitas, sampai PH 8.0. Hasil percobaan menunjukan bahwa, percobaan yang menggunakan koagulan Almunium sulfat secukupnya dan penambahan $\mathrm{Ca}(\mathrm{OH}) 2$ untuk menstabilkan $\mathrm{pH}$, sehingga diperoleh kualitas hasil pengolahan yang baik, dan sesuai dengan perfomance efluen reactor fixed bed yang jernih. Selain itu, aplikasi $\mathrm{Ca}(\mathrm{OH}) 2$ dapat membantu meningkatkan konerja koagulan yang dapat dilihat dari ukuran flok sedimentasi dari effluen anaerob
\end{abstract}

kata kunci : koagulasi, almunium sulfat

\begin{abstract}
Fixed reactor effluent from tofu waste water is still high organic in wastewater and has a lot suspended solid, therefore the colour is not so clear enough, but it is difficult to degrade it anaerobically. Base on as mentioned above, it is tried to process it with coagulation use Alumunium sulphate and $\mathrm{Ca}(\mathrm{OH})_{2}$ which is added to effluent of Fixed Bed reactor with several dosis variation of Alumunium sulphate: start from 0,5; 1,0; 1,5; 2,5; 5,0; 7,5. gram and aid of $\mathrm{Ca}(\mathrm{OH})_{2}$ will give high alkanity, until $\mathrm{pH} 8,0$. Experiment result shows the experiment which use a match Alumunium sulphate as coagulant and $\mathrm{Ca}(\mathrm{OH})_{2}$ to stabilize the $\mathrm{pH}$ could give a good quality of processing and suitable with the clear performamce of effluent Fixed Bed digester.. The application of $\mathrm{Ca}(\mathrm{OH})_{2}$ could help increasing the performance of coagulant that can be seen from the floc size sedimentation from anaerobic effluent. The objective of this experiment process is to find out more clear water
\end{abstract}

key words : coagulation. Alumunium sulphate 


\section{PENDAHULUAN}

\subsection{Koagulan}

Koagulasi adalah proses pengumpulan partikel-partikel halus yang tidak dapat diendapkan secara gravitasi, menjadi partikel yang lebih besar sehingga bisa diendapkan dengan cara menambahkan bahan koagulasi. ${ }^{1}$ Partikel-partikel tersebut kemudian dihilangkan melalui proses sedimentasi dan filtrasi. Adapun bahan kogulan yang sering dipergunakan antara lain :

$\begin{array}{ll}\text { - } & \left.\text { Tawas } \mathrm{Al}_{2} \mathrm{SO}_{4}\right)_{3} \\ \text { - } & \text { Fero Sulfat }\left(\mathrm{Fe}_{2}\left(\mathrm{SO}_{4}\right)_{3}\right. \\ \text { - } & \text { Feri Sulfat }\left(\mathrm{Fe}_{2}\left(\mathrm{SO}_{4}\right)_{3}\right. \\ \text { - } & \text { Fero Chlorida }\left(\mathrm{FeCl}_{2}\right)^{2} \\ \text { - } & \text { Poly Aluminium } \mathrm{Chlorida}_{2}\left(\mathrm{Na} \mathrm{AICl}_{3}\right) \\ & \\ & \text { Di samping bahan-bahan yang }\end{array}$ disebutkan diatas, saat ini banyak terdapat dipasaran, yaitu "Coagulant Aid" (Koagulan tambahan) yang berfungsi untuk mandapatkan air yang lebih jernih, mempercepat proses pengendapan (membantu fungsi bahan Koagulan dan mengurangi dosis Koagulan).

\section{- $\quad$ Super floc \\ - Magni floc \\ - $\quad$ Aqua floc atau \\ - Kapur}

Selain koagulan diatas baru beberapa tahun terakhir digunakan Poly Aluminium Chlorida nama dagangnya Penjernih Air Cepat yang merupakan polimer dari Aluminium koagulasi yang bermanfaat untuk menurunkan kekeruhan.

\subsection{Proses Koagulasi}

Penambahan koagulan akan mengakibatkan partikel-partikel tidak mengendap saling mendekat dan membentuk flok-flok mikro (yang ukurannya lebih besar dari pada koloidal asalnya) yang ikatannya sangat lemah dan tidak nampak dengan mata biasa tetapi tidak dapat mengendap. Pengadukan pelan-pelan akan menyebabkan flok-flok mikro mengumpul dan membentuk flok yang lebih besar dan relatif lebih berat yang akhirnya dapat dengan mudah diendapkan atau disaring. ${ }^{1)}$.

Pembentuk flok pada proses koagulasi dipengaruhi oleh factor fisika dan kimia seperti kondisi pengadukan, $\mathrm{pH}$, Alkalinitas, kekeruhan dan suhu air. Seperti alum apabila digunakan diluar kisaran $\mathrm{pH}$ optimumnya $(5,8-7,4)$, maka flok yang terbentuk akan tidak sempurna dan akan larut kembali. Namun demikian dosis bahan koagulan optimum yang ditambahkan harus ditentukan berdasarkan percobaan laboratorium dengan Jar test. ${ }^{2)}$

\section{Tawas}

Tawas dengan rumus kimia $\mathrm{Al}_{2}\left(\mathrm{SO}_{4}\right)_{3}$ (Aluminium Sulfat) merupakan bahan koagulan; yang paling banyak digunakan karena bahan ini paling ekonomis (murah), mudah didapatkan dipasaran, serta mudah penyimpanannya. Selain itu bahan ini cukup efektif untuk menurunkan kadar karbonat.

$\mathrm{Al}_{2}\left(\mathrm{SO}_{4}\right)_{3} \longrightarrow 2 \mathrm{Al}^{+3}+3 \mathrm{SO}_{4}^{-2}$ Air akan mengalami $\mathrm{H}_{2} \mathrm{O} \longrightarrow \mathrm{H}^{+}+\mathrm{OH}^{-}$ Selanjutnya $2 \mathrm{Al}^{+3}+6 \mathrm{OH}^{-} \longrightarrow 2 \mathrm{Al}(\mathrm{OH}) 3$ Selain itu akan dihasilkan asam.

$3 \mathrm{SO}_{4}^{-2}+6 \mathrm{H}^{+} \longrightarrow 3 \mathrm{H}_{2} \mathrm{SO}_{4}$ dengan demikian banyaknya dosis tawas yang ditambahkan menyebabkan $\mathrm{pH}$ makin turun, karena dihasilkan asam sulfat sehingga perlu dicari dosis tawas dan kapur optimum yang harus ditambahkan. Pemakaian tawas paling efektif antara $\mathrm{pH}$ $5,8-7,4$. apabila alkalinitas alami dari air tidak seimbang dengan dosis tawas perlu ditambah alkalinitas. Untuk pengaturan (menaikan) $\mathrm{pH}$ biasanya ditambahkan larutan kapur $\mathrm{Ca}(\mathrm{OH})_{2}$ atau soda abu $\left(\mathrm{Na}_{2}\right.$ $\left.\mathrm{CO}_{3}\right)^{4)}$. 


\section{Feri Sulfat dan Feri Chlorida}

Dengan rumus kimia $\mathrm{Fe}_{2}\left(\mathrm{SO}_{4}\right)$ dan $\mathrm{Fe}$ $\mathrm{Cl}_{3}$ bahan ini bersifat korosif, serta tidak tahan penyimpanan lama dan mempunyai sifat asam. Endapan $\mathrm{Fe}(\mathrm{OH})_{3}$ efektif terbentuk pada $\mathrm{pH} 5,5$. Untuk pengaturan $\mathrm{pH}$ biasanya ditambahkan larutan kapur. Garam feri ini biasanya dipakai untuk koagulasi air buangan industri, tetapi setelah itu harus diolah lagi untuk menghilangkan Fe yang ada dalam air tadi.

\section{Fero Sulfat dan Fero Cholrida $\left(\mathrm{FeSO}_{4}\right.$ dan $\mathrm{FeCl}_{2}$ )}

Flokulasi dengan fero ini biasanya akan lebih baik bila ditambahkan larutan kapur atau $\mathrm{NaOH}$ Fe sebagai pengatur kondisi flocculasi dengan perbandingan $2: 1$.

Reaksi dengan bikarbonat dan basa membentuk $\mathrm{Fe}(\mathrm{OH})_{2}$ yang sedikit larut, dan selanjutnya akan dioksidasi oleh Oksigen terlarut menjadi $\mathrm{Fe}(\mathrm{OH})_{3}$ yang tidak dapat larut.

\section{Kapur}

Pengaruh penambahan kapur dengan rumus $\mathrm{Ca}(\mathrm{OH})_{2}$ akan menaikan $\mathrm{pH}$ dan bereaksi dengan bikarbonat membentuk endapan $\mathrm{CaCO}_{3}$. bila kapuryang ditambahkan cukup banyak sampai $\mathrm{pH}=10,5$, maka akan terbentuk endapan $\mathrm{Mg}(\mathrm{OH})_{2}$.

Kelebihan ion $\mathrm{Ca}$ pada $\mathrm{pH}$ tinggi dapat diendapkan dengan penambahan soda abu.

\section{Reaksinya :}

$$
\begin{aligned}
& \mathrm{Ca}(\mathrm{OH})_{2}+\mathrm{Ca}\left(\mathrm{HCO}_{3}\right)_{2} \longrightarrow \\
& 2 \mathrm{CaCO}_{3}+2 \mathrm{H}_{2} \mathrm{O} . \\
& 2 \mathrm{Ca}(\mathrm{OH})_{2}+\mathrm{Mg}\left(\mathrm{HCO}_{3}\right)_{2} \longrightarrow \\
& 2 \mathrm{CaCO}_{3}+\mathrm{Mg}(\mathrm{OH})_{2}+2 \mathrm{H}_{2} \mathrm{O} \\
& \mathrm{Ca}(\mathrm{OH})_{2}+\mathrm{Na}_{2} \mathrm{CO}_{3} \longrightarrow \mathrm{CaCO}_{3}+2
\end{aligned}
$$
$\mathrm{NaOH}$.

\section{Poly Aluminium Chlorida (P A C)}

Bahan ini merupakan polimer dari Aluminium Chlorida dan baru beberapa tahun terakhir digunakan, dikemas dalam bentuk sederhana dan siap pakai. Merupakan bahan kogulasi yang bermanfaat untuk menurunkan kekeruhan.

\section{Coagulant aid (koagulan pembantu)}

Biasanya untuk mendapatkan air yang lebih jernih dan mempercepat proses pengendapan ditambahkan Coagulan aid yang berfungsi membantu/memacu proses koagulasi.

Bahan yang sering dipakai sebagai coagulant aid ialah dari bahan polymer organic. Polymer adalah bahan organic yang berat molekulnya besar. Biasanya sering disebut juga poly elektrolit.

Bahan ini ada yang asli (alamiah) dan ada yang sintetis. Polyelektrolit sintetis diklasifikasikan berdasarkan atas jenis muatan pada rantai polymer sebagai berikut :

- Anion poly elektrolit : Polymer bermuatan negatif.

- Kation poly elektrolit : Polymer bermuatan positif.

- Polyelektrolit bukan ion : Polymer tak bermuatan.

B e r m a c a m-m a c a m poly elektrolit, tergantung dari pabrik yang memproduksinya seperti :

Superfloc, Magnifloc, Kononfloc, Aquafloc dan lain sebagainya. Kisaran dosis anion dan kation poly elektrolit adalah $1-10 \mathrm{mg} / \mathrm{l}$ dan nonionic poly elektrolit.

\section{METODOLOGI}

\subsection{Percobaan Jar Test}

Gelas ukur dengan 1 Liter digunakan sebagai Jar test secara langsung dilapangan, alat tersebut digunakan untuk menentukan dosis koagulan yang optimum. Alat yang dipergunakan untuk percobaan Jar test adalah gelas ukur yang dilengkapi dengan alat-alat gelas dan pengaduk yang sempurna, atau dapat dilakukan dengan alat pengaduk sederhana misalnya dengan pengaduk batang bamboo. Bahan koagulan yang 
bisa dikerjakan untuk percobaan koagulasi adalah tawas. Sedangkan untuk pengaturan kondisi $\mathrm{pH}$ biasa digunakan kapur ${ }^{3}$.

Pada dasarnya percobaan ini meliputi :

- Menentukan dosis bahan koagulan tawas (Alum) yang ditambahkan variasi dosis tawas yang berbeda-beda. Alum dengan dosis 0,$5 ; 1,0 ; 1,5 ; 2,5 ; 5 ; 7,5$ gram.

- Percobaan pencarian dosis koagulan dilakukan dengan penambahan kapur pada larutan dari digester sehingga mencapai $\mathrm{pH} 8$ yang berguna untuk membantu menaikkan $\mathrm{pH}$ dan tawas melakukan pengendapan pada keadaan alkalis.

- Limbah cair efluen dari Fixed bed reaktor yang digunakan mempunyai $\mathrm{pH}$ awal netral sehingga perlu ditambahkan kapur atau $\mathrm{Ca}(\mathrm{OH})_{2}$ sehingga didapatkan kondisi $\mathrm{pH}$ yang alkalis dan cukup optimum.

- Dengan kondisi pH yang telah dipilih, dilakukan optimasi berapa dosis tawas yang tepat yang harus ditambahkan.

- Peralatan yang digunakan antara lain : gelas ukur,sebagai floc tester, pipet ukur, corong gelas, , $\mathrm{pH}$ meter, kertas saring, alat pengaduk,

- Bahan yang digunakan antara lain adalah contoh limbah cairan dari efluen fixed reaktor dan bahan koagulan Aluminium sulfat (tawas).

\subsection{Cara kerja}

Cara kerja yang dilakukan untuk melihat dosis koagulan gelas ukur volume 1 Liter yang disiapkan sebagai floc tester dan 1 buah gelas beaker. Ditambahkan kapur $\mathrm{Ca}(\mathrm{OH})_{2}$ bahan untuk menaikkan $\mathrm{pH}$ menjadi alkalis dan kemudian pemberian koagulan (tawas) dengan dosis yang berlainan 0,$5 ; 1,0 ; 1,5 ; 2,5 ; 5 ; 7,5$ gram, kemudian diaduk cepat selama 3 menit, setelah itu didiamkan selama 15, 30, 45, dan 60 menit. Diamati bentuk tinggi pengendapannya serta kecepatan pembentuk gumpalan pada waktu-waktu tersebut serta dilihat kejernihan efluen diatasnya kemudian diperiksa $\mathrm{pH}$, kekeruhan dan warna. Tujuan pemberian selang waktu pengendapan untuk melihat waktu terbaik untuk pembuangan endapan. Kemudian dipilih pemakaian tawas optimum yang memberikan hasil terbaik, dan bilamana tidak mencapai hasil yan cukup baik kemudian diulang dengan menggunakan koagulan. Percobaan pencarian dosis koagulan dilakukan pula dengan memberi koagulan atau $\mathrm{Ca}(\mathrm{OH})_{2}$ dengan variasi untuk membantu pembuatan flok dan pengendapan.

Limbah cair efluen fixed bed reaktor dari pabrik tahu mempunyai $\mathrm{pH}$ berkisar antara 6,48 yang perlu penambahan $\mathrm{Ca}(\mathrm{OH})_{2} /$ kapur untuk pengaturan $\mathrm{pH}$ menjadi alkalis, atau membantu proses optimum pada tawas agar diperoleh effluent yang lebih jernih.

\section{HASIL DAN PEMBAHASAN}

Pada percobaan ini limbah cair efluen Fixed Bed reaktor pabrik tahu yang digunakan mempunyai parameter $\mathrm{pH}$ sekitar 6,8 . Oleh karena $\mathrm{pH}$ limbah cair efluen fixed bed reaktor termasuk netral, maka $\mathrm{pH}$ dinaikkan dengan berbagai variasi penambahan $\mathrm{Ca}(\mathrm{OH})_{2}$ sehingga $\mathrm{pH}$ yang dicapai bervariasi dengan waktu hasil terlihat pada Gambar 1. Selanjutnya dilakukan percobaan dengan menggunakan tawas .sebagai bahan pembantu pengendap.

Berdasarkan pengamatan yang dilakukan dengan menggunakan tawas sebagai koagulan diharapkan membantu kinerja yang dilihat berdasarkan flok yang terbentuk cukup besar yang menyebabkan pengendapan.

Pada proses pemberian Alum dengan dosis yang semakin meningkat mulai dari berlainan 0,$5 ; 1,0 ; 1,5 ; 2,5 ; 5 ; 7,5$ gram, dapat dilihat terjadinya pengendapan atau kekeruhan yang kemudian cenderung 
tinggi menurun kembali pada posisi 1 jam yang terakhir. Tinggi pengendapan dilihat setiap 15 menit sekali yaitu pada 15 menit pertama, 30 menit, 45 menit dan 60 menit. Penurunan kembali tinggi endapan dapat terjadi karena terjadi keseimbangan kembali antara molekul dengan berjalannya waktu. Penambahan pemberian tawas sebagai koagulan dosis yang semakin meningkat mulai dari 0,$5 ; 1,0 ; 1,5 ; 2,5 ; 5 ; 7,5$ gram, terlihat mempunyai nilai $\mathrm{pH}$ yang semakin meningkat sedikit. Keadaan tersebut dapat dilihat pada Gambar 2. Yang memperlihatkan gambaran waktu perubahan $\mathrm{pH}$ selang waktu 15, 30, 45 dan 60 menit pada berbagai variasi pemberian dosis tawas.

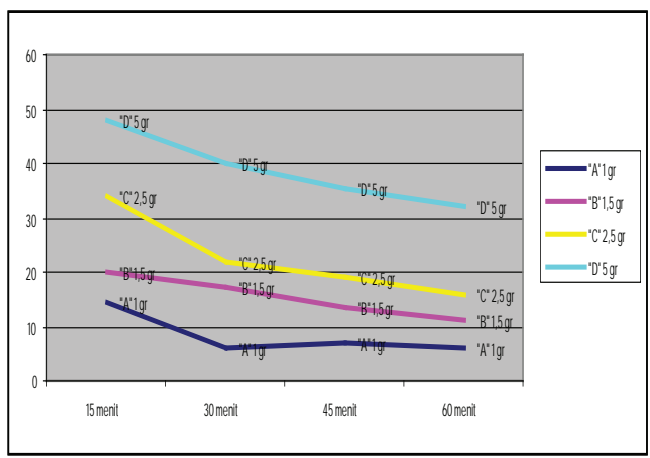

Gambar 1. Pengaruh dosis koagulan tawasterhadap pengendapan

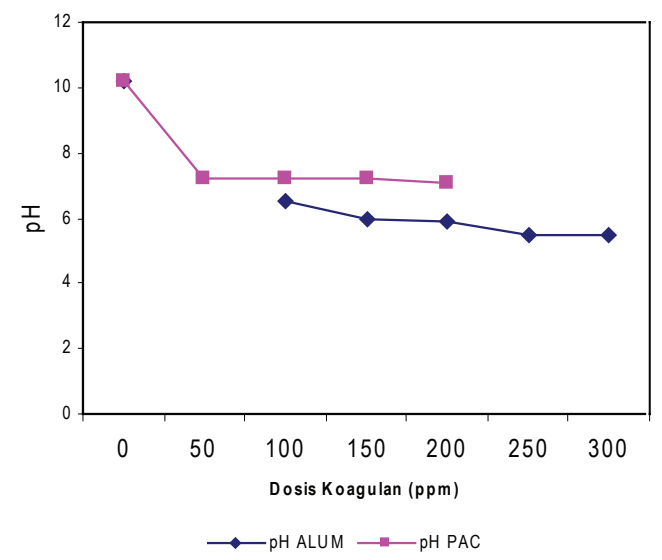

Gambar 2.Pengaruh dosis koagulan/ tawas terhadap $\mathrm{pH}$ dengan waktu tertentu.
Pengaruh dosis koagulan terhadap $\mathrm{pH}$ terlihat, pemberian dosis tawas yang meningkat tidak begitu berpengaruh yang menyebabkan $\mathrm{pH}$ semakin menaik karena tawas bekerja dalam suasana alkalis. Kejernihan dapat dilihat pada tabung yang diberi kapur agak tinggi serta tawas yang cukup banyak tapi hal ini membuat proses pengolahan menjadi mahal. Hal tersebut dapat dilihat pada Gambar 3 .

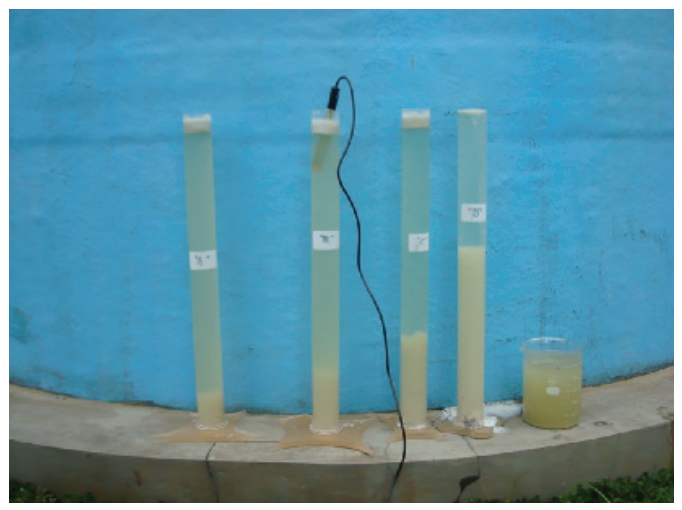

Gambar 3. Pengaruh dosis koagulan terhadap kejernihan cairan

Perbandingan kejernihan berdasar penambahan kapur dan tawas. Penambahan kapur yang cukup banyak akan menjernihkan air efluen Fixed Bed reaktor dan hasil kekeruhan yang cukup menurun dan bila dibandingkan dengan pemberian tawas lebih sedikit.

\section{KESIMPULAN}

Berdasarkan percobaan dengan menggunakan koagulan tawas yang dikondisikan dengan suasana alkalis dengan pemberian kapur atau $\mathrm{Ca}(\mathrm{OH}) 2$ memperlihatkan semakin tinggi tawas yang diberikan semakin jernih. Dosis yang tepat sekitar 2,5 gr/liter dapat memberikan kualitas hasil olahan yang cukup baik.

\section{DAFTAR PUSTAKA}

1. Metcalf \& eddy, inc: Wastewater Engineering: Collection, Treatment, 
Disposal, Mc Graw Hill, New york, 1972.

2. Perry, J.H: Chemical Engineers Hand Book, 4th ed, Mc Graw Hill, New York. 1963.

3. Physical Chemical Wastewater Treatment Plant Design U.S.
Environmental Protection Agency, Technology Transfer Seminar Publication, 1973.

4. Schroeder, E.D : Water and Wastewater Treatment Mc.Graw Hill, New York 1977. 